\title{
Correction to: $a$-Phellandrene attenuates tissular damage, oxidative stress, and TNF-a levels on acute model ifosfamide-induced hemorrhagic cystitis in mice
}

\author{
R. L. G. Gonçalves ${ }^{1}$ - F. V. M. Cunha ${ }^{1}$ - B. P. S. Sousa-Neto ${ }^{1}$ - L. S. A. Oliveira ${ }^{1}$ - M. E. Lopes ${ }^{1}$ - D. C. Rezende ${ }^{1}$

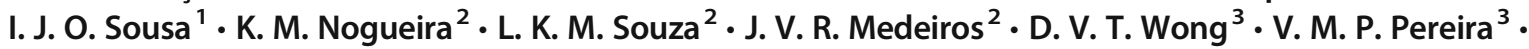 \\ R. C. P. Lima-Júnior ${ }^{3}$ - D. P. Sousa ${ }^{4}$. C. P. C. Oliveira ${ }^{5}$ F. R. C. Almeida ${ }^{1} \cdot$ Francisco de Assis Oliveira $^{1}$
}

Published online: 16 October 2020

(C) Springer-Verlag GmbH Germany, part of Springer Nature 2020

Correction to: Naunyn-Schmiedeberg's Archives of Pharmacology (2020) 393:1835-1848

https://doi.org/10.1007/s00210-020-01869-3

The published online version contains figure in poor quality. The updated figure is shown below:

The online version of the original article can be found at https://doi.org/ $10.1007 / \mathrm{s} 00210-020-01869-3$

Francisco de Assis Oliveira

fassisol@ufpi.edu.br

1 Medicinal Plants Research Center, Federal University of Piauí, Av. Nossa Senhora de Fátima s/n, Teresina, PI 64049-550, Brazil

2 Experimental Physiopharmacology of Gastrointestinal Disorders, Federal University of Piauí, Av. São Sebastião, no 2819,

Parnaíba, Piauí 64202-020, Brazil

3 Department of Physiology and Pharmacology, Faculty of Medicine, Universidade Federal do Ceará, Rua Cel. Nunes de Melo, 1127, Fortaleza, Ceará 60430-270, Brazil

4 Department of Pharmaceutical Sciences, Federal University of Paraíba, Centro de Ciências da Saúde, João

Pessoa, Paraíba 58059-900, Brazil

5 Department of Community Medicine, Federal University of Piaú, Av. Nossa Senhora de Fátima s/n, Teresina, PI 64049-550, Brazil 
95\% Family-wise confidence level

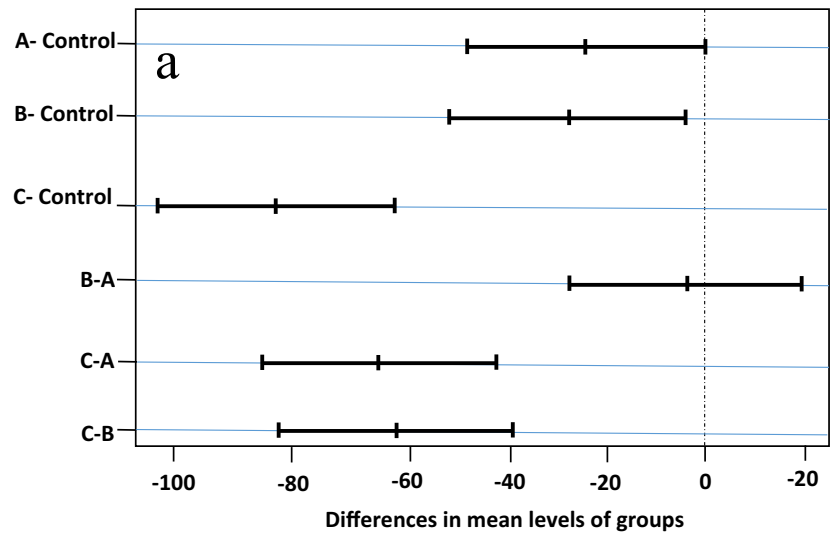

Publisher's note Springer Nature remains neutral with regard to jurisdictional claims in published maps and institutional affiliations.
95\% Family-wise confidence level

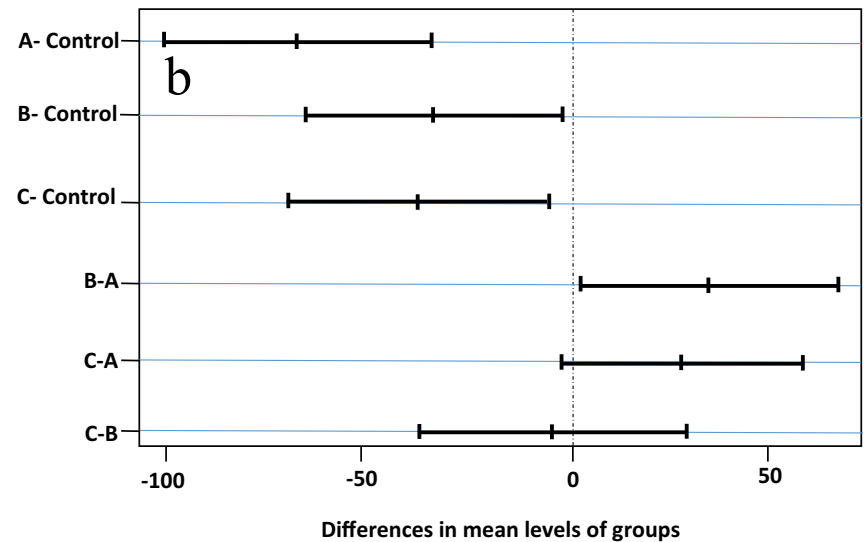

